Check for updates

Cite this: RSC Adv., 2019, 9, 32382

Received 31st August 2019

Accepted 1st October 2019

DOI: $10.1039 / c 9 r a 06914 c$

rsc.li/rsc-advances

\section{Dual-doped hierarchical porous carbon derived from biomass for advanced supercapacitors and lithium ion batteries $\uparrow$}

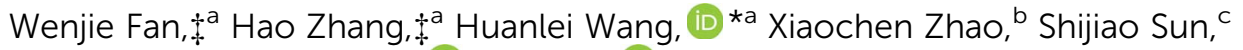 \\ Jing Shi, ${ }^{a}$ Minghua Huang, (DD ${ }^{a}$ Wei Liu, (iD ${ }^{a}$ Yulong Zheng ${ }^{a}$ and Ping $\mathrm{Li}^{\mathrm{a}}$
}

Nowadays, designing heteroatom-doped porous carbons from inexpensive biomass raw materials is a very attractive topic. Herein, we propose a simple approach to prepare heteroatom-doped porous carbons by using nettle leaves as the precursor and $\mathrm{KOH}$ as the activating agent. The nettle leaf derived porous carbons possess high specific surface area (up to $1951 \mathrm{~m}^{2} \mathrm{~g}^{-1}$ ), large total pore volume (up to $1.374 \mathrm{~cm}^{3} \mathrm{~g}^{-1}$ ), and high content of nitrogen and oxygen heteroatom doping (up to 17.85 at\% combined). The obtained carbon as an electrode for symmetric supercapacitors with an ionic liquid electrolyte can offer a superior specific capacitance of $163 \mathrm{~F} \mathrm{~g}^{-1}$ at $0.5 \mathrm{~A} \mathrm{~g}^{-1}$ with a capacitance retention ratio as high as $67.5 \%$ at $100 \mathrm{~A} \mathrm{~g}^{-1}$, and a low capacitance loss of $8 \%$ after 10000 cycles. Besides, the as-built supercapacitor demonstrates a high specific energy of $50 \mathrm{~W} \mathrm{~h} \mathrm{~kg}^{-1}$ at a specific power of $372 \mathrm{~W} \mathrm{~kg}^{-1}$, and maintains $21 \mathrm{~W} \mathrm{~h} \mathrm{~kg}^{-1}$ at the high power of $40 \mathrm{~kW} \mathrm{~kg}^{-1}$. Moreover, the resultant carbon as a Li-ion battery anode delivers a high reversible capacity of $1262 \mathrm{~mA} \mathrm{~h} \mathrm{~g}{ }^{-1}$ at $0.1 \mathrm{~A} \mathrm{~g}^{-1}$ and $730 \mathrm{~mA} \mathrm{~h} \mathrm{~g}^{-1}$ at $0.5 \mathrm{~A} \mathrm{~g}^{-1}$, and maintains a high capacity of $439 \mathrm{~mA} \mathrm{~h} \mathrm{~g}^{-1}$ after 500 cycles at $1 \mathrm{~A} \mathrm{~g}^{-1}$. These results demonstrate that the nettle leaf derived porous carbons offer great potential as electrodes for advanced supercapacitors and lithium ion batteries.

\section{Introduction}

Under the dual challenge of fossil fuel depletion and global warming, the demand of global energy is developing towards cleanliness, diversification, renewability and efficiency. ${ }^{1,2}$ The exploitation of sustainable energy materials, and their related devices with high energy and power density, have been in full swing in the last few years. Among the existing energy storage devices, supercapacitors (SCs) and lithium ion batteries (LIBs) have attracted tremendous attention due to high energy characteristics of batteries and high power features of supercapacitors. ${ }^{3-7}$ However, SCs still have the disadvantage of low energy density, and LIBs also need to solve the problem of poor rate performance and cycling life. ${ }^{5,8-11}$ Carbon materials have been extensively applied as electrode materials for SCs and LIBs due to easy availability, controllable microstructure and

\footnotetext{
${ }^{a}$ School of Materials Science and Engineering, Ocean University of China, Qingdao 266100, People's Republic of China. E-mail: huanleiwang@gmail.com; huanleiwang@ouc.edu.cn

${ }^{b}$ College of Marine Science and Biological Engineering, Qingdao University of Science and Technology, Qingdao, Shandong 266042, China

${ }^{\circ}$ College of Materials Science and Engineering, Nanjing Tech University, Nanjing 210009, People's Republic of China

$\dagger$ Electronic supplementary information (ESI) available. See DOI: $10.1039 / \mathrm{c} 9 \mathrm{ra} 06914 \mathrm{c}$

$\$$ These authors contribute equally to this work.
}

morphology, high conductivity and stable physicochemical properties. ${ }^{8,9,12}$ Unfortunately, as the dominant commercial electrode materials for SCs, traditional activated carbons exhibit low gravimetric capacitance and poor rate capability due to the pore tortuosity as well as high fraction of microporosity. Moreover, the low theoretical capacity $\left(372 \mathrm{~mA} \mathrm{~h} \mathrm{~g}^{-1}\right)$ as well as inferior ion transport kinetics of commercial graphite-based electrode can't satisfy the increasing requirement for LIBs. ${ }^{5,13}$ Therefore, new carbon materials with high capacity and rate performance are being extensively explored to improve the above issues faced for SCs and LIBs.

Recently, various carbon materials with different morphologies and structures, such as porous carbon, ${ }^{14,15}$ carbon nanofiber $^{5,16}$ and graphene, ${ }^{17}$ have been widely investigated. Among them, hierarchical porous carbons with high surface area show great potential as advanced electrodes for SCs and LIBs, since the hierarchical structure can shorten ion diffusion distance and reduce ion transport time, and the high surface area can enlarge electrode/electrolyte interface for charge storage. ${ }^{18,19} \mathrm{In}$ addition, heteroatom doping (like $\mathrm{N}, \mathrm{O}$, and S) can also enhance the electrochemical performance, since the existence of heteroatoms on the surface or inside of the carbon framework can increase the reactive activity and offer lots of ion storage sites. ${ }^{20-22}$ Compared with single heteroatom doping, co-doping can further enhance electrochemical properties of the carbon materials owing to the synergistic effect. ${ }^{23-27}$ For example, 
nitrogen and oxygen have received considerable attention for improving the wettability between electrolyte and electrode material and facilitating the occurrence of surface redox reaction further to achieve extra pseudocapacitance. . $^{1324}$

As a kind of natural resource, biomass has been considered as potential precursor for the preparation of carbon materials owing to its easily available, fast-renewable, low-cost and environmentally benign features. ${ }^{26,28-30}$ Consequently, carbon materials derived from biomass (including hemp, ${ }^{8}$ cattle bone, ${ }^{12}$ ginkgo leaves, ${ }^{31}$ honeysuckle, ${ }^{23}$ wheat stalk, ${ }^{32}$ bamboo pulps ${ }^{33}$ peat moss, ${ }^{34}$ and rice husk,${ }^{35}$ and cotton ${ }^{36}$ ) by pyrolysis/ activation process as electrodes for SCs and LIBs have been explored. In addition, due to the variety of microstructures of natural biomass, the as prepared carbon materials can exhibit different structures, ${ }^{37,38}$ which can offer favorable capacitance, high rate capability and long cycling life. For example, Feng et al. produced nitrogen-doped porous carbon flakes through using human hair as precursor, which can display high specific capacitance of $340 \mathrm{~F} \mathrm{~g}^{-1}$ at $1 \mathrm{~A} \mathrm{~g}^{-1}$ and excellent cycling stability with capacitance retention of $98 \%$ after 20000 cycles. ${ }^{39}$ Wang et al. prepared cattle bone derived carbon for LIBs, which can maintain a high specific capacity of $281 \mathrm{~mA} \mathrm{~h} \mathrm{~g}^{-1}$ at $30 \mathrm{~A} \mathrm{~g}^{-1}$ and $1488 \mathrm{~mA} \mathrm{~h} \mathrm{~g}^{-1}$ after 250 cycles at $1 \mathrm{~A} \mathrm{~g}^{-1} \cdot{ }^{12}$ This indicates that exploiting biomass derived carbon materials with high electrochemical performance is significantly needed.

As one common weed, nettle is widely distributed in China. Thousands of tons of nettle leaves are produced each year. However, nettle leaves have not been fully used. Except for utilization as medicine and animal feed, a large amount of nettle leaves is abandoned in the wild as natural waste. Therefore, it is pivotal to find an effective approach to utilize this waste resource. In fact, nettle leaves contain the composition of proteins, fat, carbohydrate, cellulose, sugars, and mineral elements (like $\mathrm{Na}, \mathrm{K}$, and $\mathrm{Mg}$ ), which can be adopted as a cheap, environmentally friendly and widespread precursor to prepare carbon materials with a high value application. The carbon materials prepared by nettle leaves can be employed as electrode materials for SCs and LIBs. Moreover, the above-mentioned components can convert substantial heteroatoms (such as $\mathrm{N}, \mathrm{O}$ ) in the carbon structure, which can further facilitate the electrochemical properties of the as-obtained carbon materials. Herein, we selected a combined carbonization-activation strategy for the synthesis of nitrogen and oxygen dual-doped hierarchical porous carbons by utilizing nettle leaves as the biomass precursor and potassium hydroxide as the activating agent. The heteroatom doping, porosity, and specific surface area can be controlled by the carbonization temperature. The N, O co-doped nettle leaf derived porous carbons show high specific surface area (as high as $1951 \mathrm{~m}^{2} \mathrm{~g}^{-1}$ ), hierarchical porous structure, and abundant content of nitrogen (1.135.49 at\%) and oxygen (6.24-12.36 at\%). When examined as electrode materials for SCs and LIBs, the as-obtained carbons can provide good charge storage capacity, excellent rate performance, and long cycle life, demonstrating that they are very promising electrode materials for advanced energy storage applications.

\section{Experimental}

\subsection{Material synthesis}

The nettle leaves were obtained from Dayi in Chengdu, China. The collected nettle leaves were washed repeatedly with distilled water and dried at $80{ }^{\circ} \mathrm{C}$ for $12 \mathrm{~h}$ before use. Nettle leaves were first mixed with $100 \mathrm{~mL} \mathrm{KOH}$ aqueous solution and the mixture was stirred at room temperature for $24 \mathrm{~h}$. Then, the mixture was transferred to an oven and dried at $80^{\circ} \mathrm{C}$ for $24 \mathrm{~h}$. Carbonization and activation was carried out by heating the obtained dried nettle leaves $/ \mathrm{KOH}$ composite to the target temperature $\left(700-900{ }^{\circ} \mathrm{C}\right)$ for $1 \mathrm{~h}$ under $\mathrm{N}_{2}$ atmosphere at a heating rate of $3{ }^{\circ} \mathrm{C} \mathrm{min}^{-1}$. Finally, the carbonized product was thoroughly washed for several times with $2 \mathrm{M}$ $\mathrm{HCl}$ and distilled water, filtered, and dried at $80{ }^{\circ} \mathrm{C}$ for $24 \mathrm{~h}$. The resultant Nettle Leaf Derived Porous Carbon was named as NLDPC- $T-n$, where $T$ represents the carbonization temperature as well as $n$ indicates the mass ratio of nettle leaves to $\mathrm{KOH}$.

\subsection{Material characterization}

The morphology and microstructure were characterized by using scanning electron microscopy (SEM, S4800, Hitachi, 15 $\mathrm{kV}$ ) and transmission electron microscopy (TEM, JEM 2010F, $200 \mathrm{kV}$ ). X-Ray diffraction (XRD) was recorded on Bruker D8 Advance X-ray diffractometer (Ni-filtered $\mathrm{Cu} \mathrm{K} \alpha$ radiation). Raman spectra were measured using a Raman Spectrometer (Lab RAM HR800) with a laser wavelength of $532 \mathrm{~nm}$ and an effective laser power on the sample of $5 \mathrm{~mW}$. The gas adsorption-desorption isotherm was measured with a Micromeritics 3 Flex $^{\mathrm{TM}}$ surface characterization analyzer at $77 \mathrm{~K}$ by using a relative pressure $P / P_{\mathrm{o}}$ of $0-0.99$ and nitrogen as the adsorbate. The pore volume and pore size distribution were estimated by density functional theory (DFT) model and the specific surface area was determined based on BrunauerEmmett-Teller (BET) method. Elemental compositions of the samples were analyzed by X-ray photoelectron spectroscope (XPS) using a multifunctional image electron spectrometer (ESCALAB 250Xi, Thermo Fisher) with Al $\mathrm{K} \alpha$ radiation of $1486.6 \mathrm{eV}$ as the excitation source. Elemental analysis was done by a conventional combustion method (CHN, Vario EL cube). The packing densities of the carbon samples were measured by using a cylindrical rod to press amounts of sample in a mold at a pressure of $10 \mathrm{MPa}$. The measurements were repeated three times with an error smaller than $3 \%$.

\subsection{Electrochemical measurement}

For SCs tests, a two-electrode system in a CR2032 corn-type cell was selected to measure the electrochemical performance. Working electrodes were prepared by mixing NLDPCs (80 wt $\%)$, Super P (10 wt \%), polyvinylidene fluoride binder (PVDF, $10 \mathrm{wt} \%$ ) in 1-methyl-2-pyrrolidinone to form a uniform slurry, and then the slurry was coated on stainless steel foil followed by drying at $80{ }^{\circ} \mathrm{C}$ for $12 \mathrm{~h}$. The mass loading of the active material was about $2 \mathrm{mg} \mathrm{cm}{ }^{-2}$. The thickness of the electrode material is in range of $50-80 \mu \mathrm{m}$. A Celgard 3501 was 
used as the separator and the 1-ethyl-3-methylimidazolium tetrafluoroborate $\left(\mathrm{EMIM}-\mathrm{BF}_{4}\right)$ was employed as the electrolyte. The cell was assembled in an Ar filled glovebox $(<0.1 \mathrm{ppm}$ of both $\mathrm{O}_{2}$ and $\mathrm{H}_{2} \mathrm{O}$ ). The cyclic voltammetry (CV), galvanostatic charge-discharge (GCD), and electrochemical impedance spectroscopy (EIS) was carried out on Gamry Interface 5000 workstation. The specific capacitance $C\left(\mathrm{~F} \mathrm{~g}^{-1}\right)$, specific energy density $\left(E, \mathrm{~W} \mathrm{~h} \mathrm{~kg}{ }^{-1}\right)$ and power density $\left(P, \mathrm{~W} \mathrm{~kg}^{-1}\right)$ calculated from the GCD curves was based on the following equations:

$$
\begin{gathered}
C=\frac{2 \times I \times \Delta t}{\Delta V \times m} \\
E=\frac{C \times \Delta V^{2}}{2 \times 4 \times 3.6} \\
P=\frac{E \times 3600}{\Delta t}
\end{gathered}
$$

where $I(\mathrm{~A})$ is the discharge current, $\Delta t(\mathrm{~s})$ is the discharge time, $m(\mathrm{~g})$ is the mass of active material on a single electrode, and $\Delta V$ (V) is the discharge voltage excluding the IR drop.

For the LIBs tests, the electrochemical characterizations were also carried out in CR2032 coin cells by using Land battery measurement system (CT2001A) and Gamry Interface 5000 workstation at room temperature. 75 wt $\%$ NLDPCs, $15 \mathrm{wt} \%$ super $\mathrm{P}$, and $10 \mathrm{wt} \%$ PVDF were coated on $\mathrm{Cu}$ foil for preparing the working electrode. The mass loading and the thickness of the electrode were about $2 \mathrm{mg} \mathrm{cm}^{-2}$ and 50-80 $\mu \mathrm{m}$. CR2032 coin cells were fabricated by employing the working electrode, Li metal foil as the counter electrode, $1 \mathrm{M}$ $\mathrm{LiPF}_{6}$ (solution with ethylene carbonate-dimethyl carbonate) as the electrolyte, polyethylene as the separator in Ar-filled glovebox.

\section{Results and discussion}

\subsection{Structural characterization of NLDPCs}

Scheme 1 illustrates the synthesis procedure of the nettle leaf derived porous carbons. In the first step, the dried nettle leaves were immersed in $\mathrm{KOH}$ aqueous solution with different concentrations. After drying, the mixture was treated by onestep carbonization/activation under different temperatures in nitrogen. Both the reaction temperature and the $\mathrm{KOH}$ mass loading can affect the specific surface area and content of nitrogen and oxygen as well as porous structure, which can play a pivotal role in the electrochemical properties. Finally, the NLDPCs were washed by hydrochloric acid and distilled water thoroughly. During the carbonization/activation process, the nitrogen and oxygen in the as mentioned proteins, fat and cellulose can be inherited, leading to the self-doped carbon structure.

The morphology of the nettle leaf derived porous carbons is shown in Fig. $1 \mathrm{a}$ and $\mathbf{S 1}, \uparrow$ which was examined by SEM. It can be observed that NLDPCs displays block-like morphology $(\sim 0.5-17$ $\mu \mathrm{m})$ with lots of macropores, which were formed during the carbonization and activation procedure. Furthermore, such open architecture of NLDPCs can facilitate the ion penetration/ diffusion on the electrode/electrolytes interface, and the abundant macropores can serve as ion-buffering reservoirs. ${ }^{\mathbf{1 4 , 2 8 , 4 0 , 4 1}}$ It can be found that the carbon matrix becomes smaller and thinner with the increase of activation temperature and $\mathrm{KOH}$ mass loading. TEM analysis was used to further explore the microstructure of NLDPCs. From the low-magnification TEM micrographs (Fig. 1b-d), it can be discovered that abundant micro/meso pores randomly oriented on the surface of the NLDPCs, which can not only increase the accessible electrode/ electrolytes interface, but also shorten the ion transport length with a minimized high-rate diffusional loss. ${ }^{24,42}$ In addition, the high-resolution TEM micrographs were demonstrated in the inserts of Fig. 1b-d, which indicate the highly

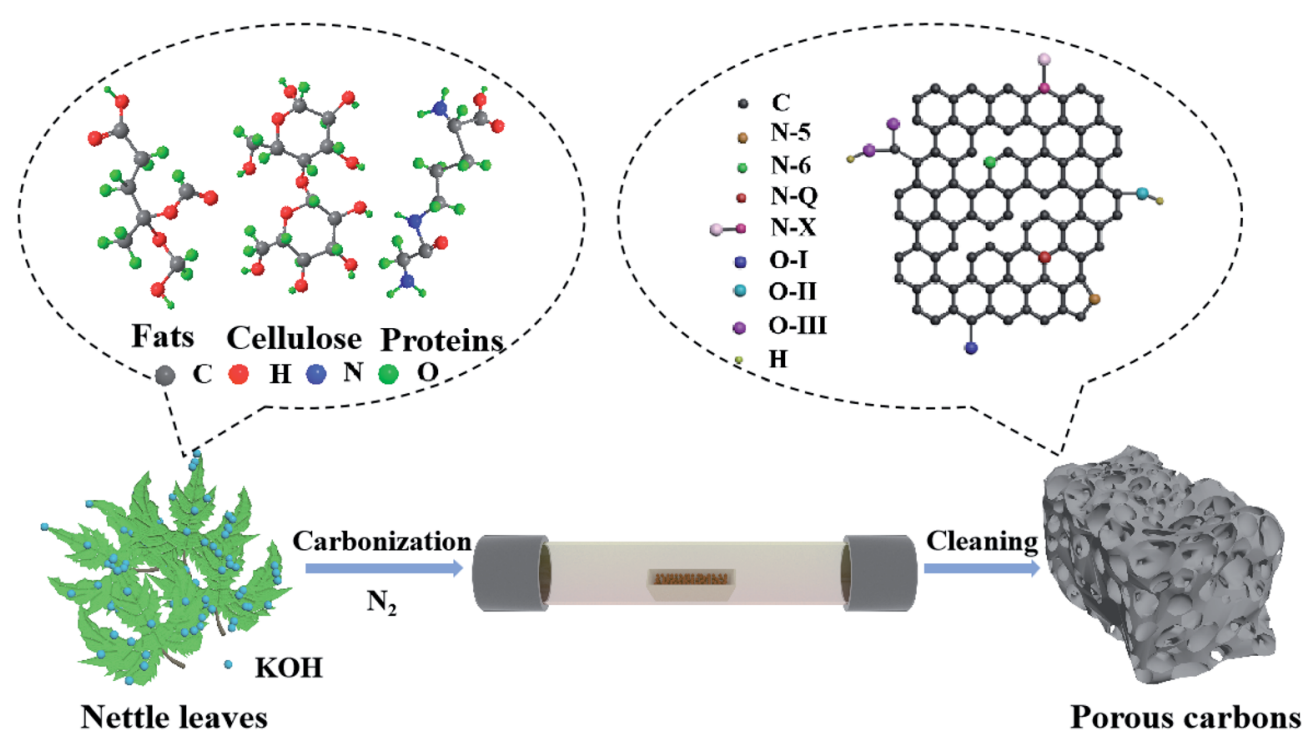

Scheme 1 Illustration of the preparation of the nettle leaf derived porous carbons. 

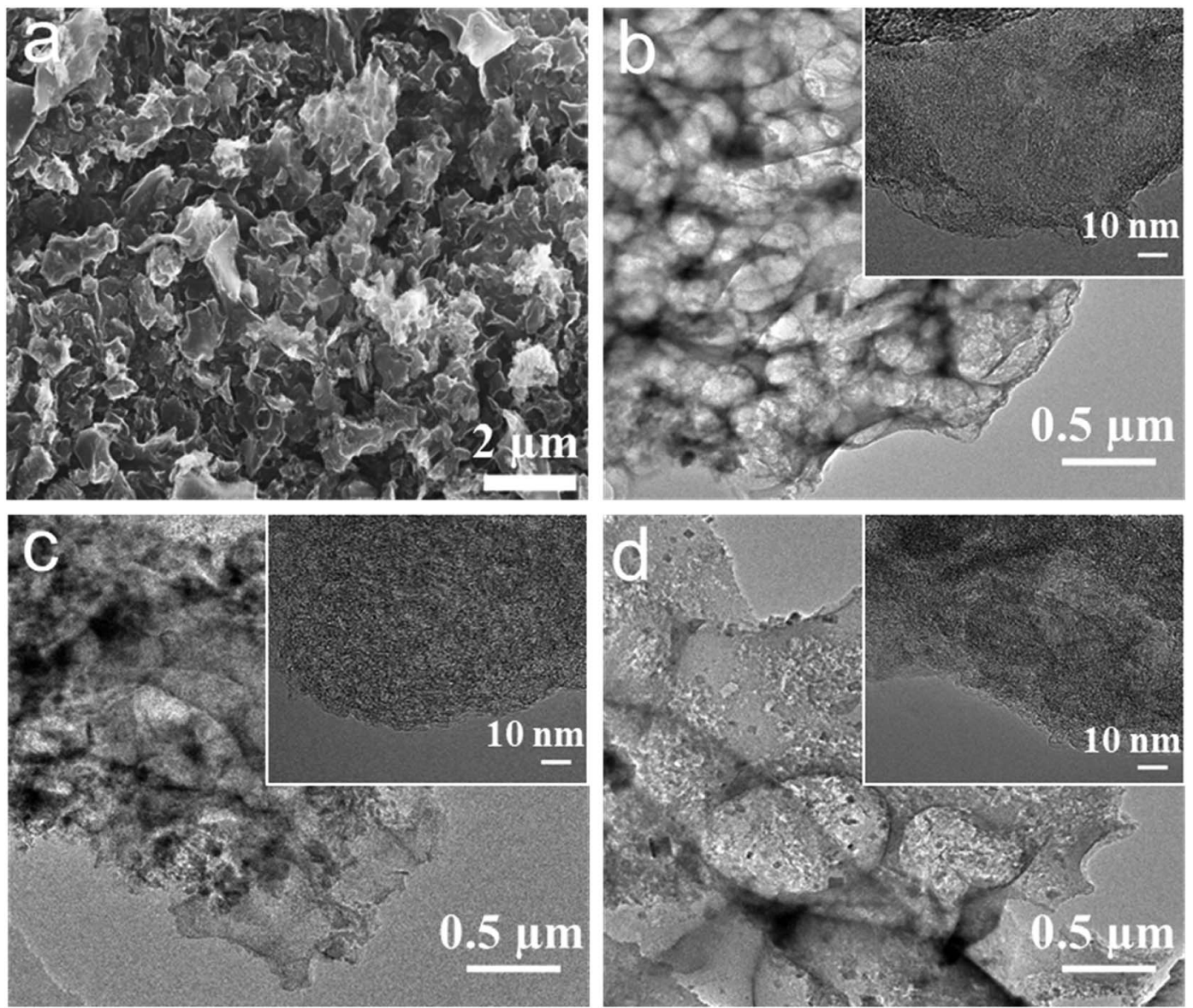

Fig. 1 (a) SEM micrographs of NLDPC-800-4-2. TEM micrographs of (b) NLDPC-800-4-1, (c) NLDPC-800-4-2, and (d) NLDPC-800-4-3.

porous but partially curved graphitic structure. It is worth nothing that the defective structure can provide more active sites for ion adsorption and intercalation..$^{18,43,44}$ The mentioned morphological and structural characteristics of NLDPCs is beneficial for the application of SCs and LIBs.

For evaluating the graphitization degree and the structural change of the NLDPCs, XRD and Raman measurements were adopted. As seen in Fig. 2a, there are two main characteristic peaks at approximately $2 \theta=25^{\circ}$ and $2 \theta=42-43^{\circ}$ for NLDPCs in the XRD patterns, which can be indexed as the (002) and (100) planes of graphite. The broad and weak diffraction peaks can confirm the amorphous or disordered state of NLDPCs. The distance of the inter-graphene layer $\left(d_{002}\right)$ calculated by Bragg equation is around $0.35 \mathrm{~nm}$ on basic of the (002) peaks and the $c$-axis length of the graphite lattice $\left(L_{c}\right)$ calculated by well-known Scherrer equation is about $0.58-0.81 \mathrm{~nm}$ on basic of the (002) peaks (Table 1). It can be found that 2-3 stacked graphitic layers are distributed in the nettle leaf derived porous carbons (e.g. $0.81 / 0.35=2.31),{ }^{45}$ in consistent with the TEM observation. The Raman spectra of NLDPCs shown in Fig. $2 b$ demonstrates overlapped D-band at $1337-1345 \mathrm{~cm}^{-1}$ (related to defective graphitic structures) and G-band at $1597-1605 \mathrm{~cm}^{-1}$ (related to the $\mathrm{sp}^{2}$-hybridized carbon). ${ }^{19}$ It is established that the intensity ratio between $\mathrm{D}$-band and G-band (i.e. $I_{\mathrm{D}} / I_{\mathrm{G}}$ ) and the full-width- at-half-maximum (FWHM) generally indicate the disorder degree of carbon materials (the fits of these two overlapping bands can be seen in Fig. S2 $\dagger$ ). ${ }^{24,46}$ As shown in Table S1, $\dagger$ the value of $I_{\mathrm{D}} / I_{\mathrm{G}}$ is 2.54 for NLDPC-700-4-2, 2.32 for NLDPC-800-4-2 and 2.10 for NLDPC-900-4-2. Moreover, the NLDPCs have a narrower FWHM of D-mode with the increase of the activation temperature, from $136 \mathrm{~cm}^{-1}$ for NLDPC-700-4-2 to $126 \mathrm{~cm}^{-1}$ for NLDPC-800-4-2 and $119 \mathrm{~cm}^{-1}$ for NLDPC-900-4-2, and a narrower FWHM of G-mode from $76 \mathrm{~cm}^{-1}$ for NLDPC-700-4-2 to $74 \mathrm{~cm}^{-1}$ for NLDPC-800-4-2 and $73 \mathrm{~cm}^{-1}$ for NLDPC-900-4-2. Therefore, it means that higher graphitization degree can be realized at high temperature. However, it can be found that the value of $I_{\mathrm{D}} / I_{\mathrm{G}}$ increased from 1.72 for NLDPC-800-4-1 to 2.88 for NLDPC-800-4-3 and the FWHM of D-mode also increased from $121 \mathrm{~cm}^{-1}$ for NLDPC-800-4-1 to $130 \mathrm{~cm}^{-1}$ for NLDPC-800-4-3, which can be conjectured that high concentration of $\mathrm{KOH}$ can promote the activation effect, i.e. producing more disordered regions and defects. ${ }^{47,48}$

In order to get more details about the porosity of NLDPCs, the $\mathrm{N}_{2}$ adsorption/desorption isotherms analysis was employed. As exhibited in Fig. $2 \mathrm{c}$ and Table 1, it could be observed that the activation temperature and the concentration of $\mathrm{KOH}$ can be considered as the important factors to adjust the overall porosity of NLDPCs. As the activation temperature or the $\mathrm{KOH}$ 

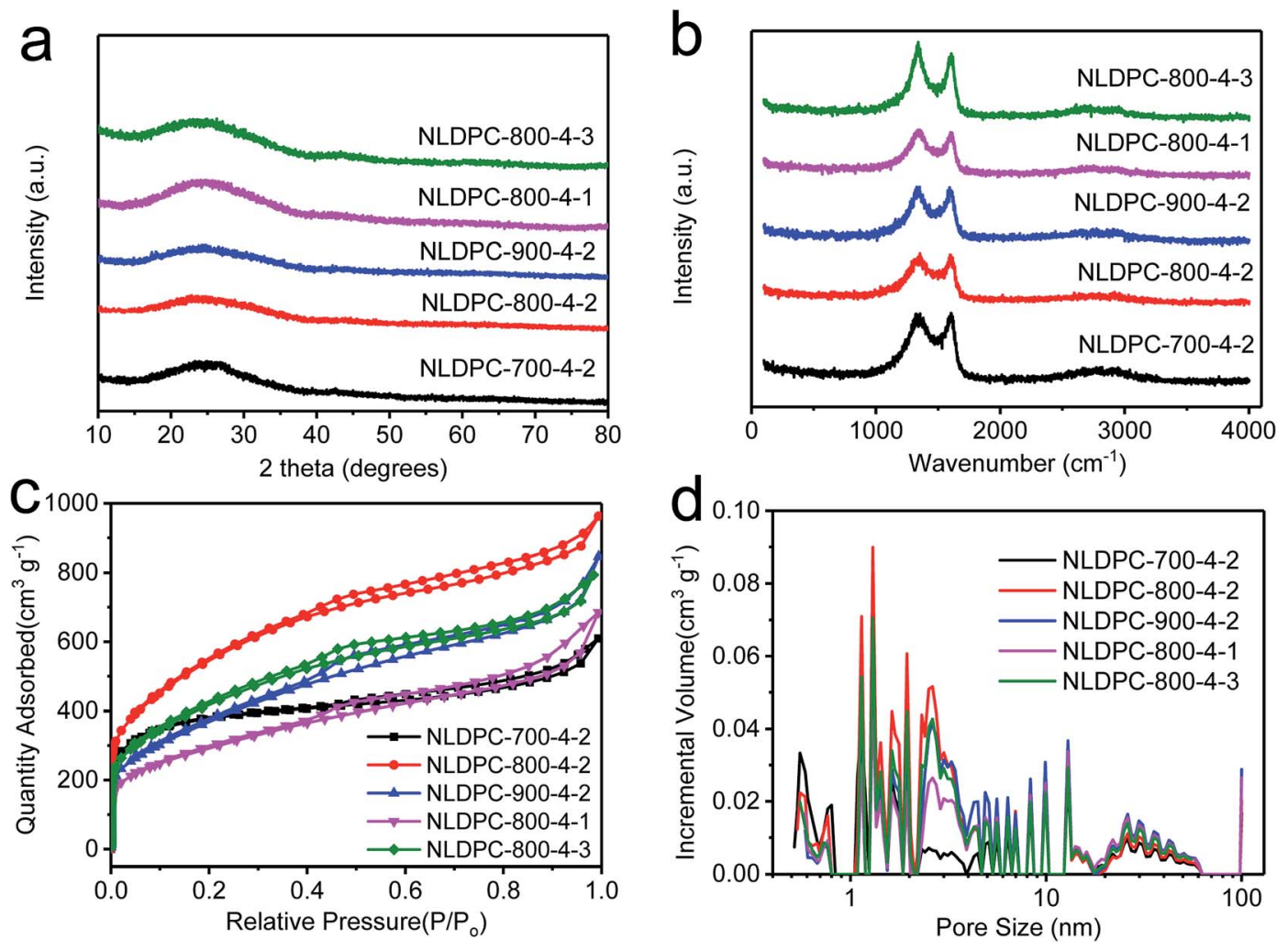

Fig. 2 (a) XRD patterns of NLDPC samples. (b) Raman spectra of NLDPC samples. (c) Nitrogen sorption analysis and (d) the related pore size distributions of NLDPC samples.

mass loading increase, the specific surface area of NLDPCs increases first and then decreases. The specific surface area calculated by Brunauer-Emmett-Teller (BET) method goes from $1373 \mathrm{~m}^{2} \mathrm{~g}^{-1}$ for NLDPC-700-4-2 to $1951 \mathrm{~m}^{2} \mathrm{~g}^{-1}$ for NLDPC-8004-2 and $1351 \mathrm{~m}^{2} \mathrm{~g}^{-1}$ for NLDPC-900-4-2, and from $1055 \mathrm{~m}^{2} \mathrm{~g}^{-1}$ for NLDPC-800-4-1 to $1507 \mathrm{~m}^{2} \mathrm{~g}^{-1}$ for NLDPC-800-4-3. It is worth mentioning that typical type IV adsorption-desorption isotherms are observed for the NLDPCs samples, which display a sharp adsorption at a relatively low pressure $\left(P / P_{\mathrm{o}}<0.01\right),{ }^{49}$ and an obvious hysteresis loop at the medium-high pressure $(P /$ $\left.P_{\mathrm{o}}>0.4\right)$. Such characteristic demonstrates that NLDPCs possess abundant micropores and highly developed and enlarged mesopores. Moreover, the existence of macropores can be verified by the slight rising slope at the relatively high pressure $\left(P / P_{\mathrm{o}}=0.95-0.99\right) .{ }^{50}$ It should be pointed out that the above analysis results are consistent with the SEM and TEM results. The $\mathrm{KOH}$ activation mainly refers to the reaction of $\mathrm{KOH}$ and $\mathrm{C}$ $\left(6 \mathrm{KOH}+2 \mathrm{C}=2 \mathrm{~K}+3 \mathrm{H}_{2}+2 \mathrm{~K}_{2} \mathrm{CO}_{3}\right)$, and the decomposition of

Table 1 Physical parameters for the nettle leaf derived porous carbons

\begin{tabular}{|c|c|c|c|c|c|c|c|c|c|c|c|c|c|c|c|c|}
\hline \multirow[b]{2}{*}{ Sample } & \multirow[b]{2}{*}{$S_{\mathrm{BET}}{ }^{a}\left(\mathrm{~m}^{2} \mathrm{~g}^{-1}\right)$} & \multirow[b]{2}{*}{$V_{\mathrm{t}}^{b}\left(\mathrm{~cm}^{3} \mathrm{~g}^{-1}\right)$} & \multirow[b]{2}{*}{$\rho^{c}\left(\mathrm{~g} \mathrm{~cm}^{-3}\right)$} & \multicolumn{3}{|c|}{ Pore volume (\%) } & \multirow[b]{2}{*}{$d_{002}(\mathrm{~nm})$} & \multirow[b]{2}{*}{$L_{a}(\mathrm{~nm})$} & \multirow[b]{2}{*}{$L_{c}(\mathrm{~nm})$} & \multicolumn{3}{|c|}{$\begin{array}{l}\text { XPS } \\
\text { composition } \\
\text { (wt\%) }\end{array}$} & \multicolumn{4}{|c|}{$\begin{array}{l}\text { Elemental analysis } \\
(\mathrm{wt} \%)\end{array}$} \\
\hline & & & & $V_{<2 \mathrm{~nm}}$ & $V_{2-50 \mathrm{~nm}}$ & $V_{>50 \mathrm{~nm}}$ & & & & $\mathrm{C}$ & $\mathrm{N}$ & $\mathrm{O}$ & $\mathrm{C}$ & $\mathrm{N}$ & $\mathrm{O}$ & $\mathrm{H}$ \\
\hline $\begin{array}{l}\text { NLDPC-700-4- } \\
2\end{array}$ & 1373 & 0.868 & 0.68 & 56.33 & 40.27 & 3.40 & 0.354 & 1.14 & 0.81 & 78.21 & 6.10 & 15.69 & 75.59 & 4.461 & 16.17 & 0.88 \\
\hline $\begin{array}{l}\text { NLDPC-800-4- } \\
2\end{array}$ & 1951 & 1.374 & 0.60 & 40.22 & 57.21 & 2.57 & 0.352 & 0.70 & 0.58 & 84.50 & 3.68 & 11.82 & 80.49 & 1.671 & 13.56 & 0.48 \\
\hline $\begin{array}{l}\text { NLDPC-900-4- } \\
2\end{array}$ & 1351 & 1.216 & 0.56 & 27.78 & 68.06 & 4.16 & 0.350 & 0.65 & 0.57 & 89.25 & 2.63 & 8.12 & 83.82 & 0.861 & 10.77 & 0.35 \\
\hline $\begin{array}{l}\text { NLDPC-800-4- } \\
1\end{array}$ & 1055 & 0.986 & 0.75 & 29.33 & 65.94 & 4.73 & 0.353 & 0.66 & 0.59 & 80.76 & 4.50 & 14.74 & 80.17 & 2.411 & 13.61 & 0.31 \\
\hline $\begin{array}{l}\text { NLDPC-800-4- } \\
3\end{array}$ & 1507 & 1.152 & 0.51 & 35.94 & 62.91 & 1.15 & 0.352 & 1.52 & 0.60 & 88.23 & 1.28 & 10.49 & 82.56 & 1.321 & 12.75 & 0.37 \\
\hline
\end{tabular}


$\mathrm{K}_{2} \mathrm{CO}_{3}\left(\mathrm{~K}_{2} \mathrm{CO}_{3}=\mathrm{K}_{2} \mathrm{O}+\mathrm{CO}_{2}\right) \cdot{ }^{18}$ Therefore, the hierarchical porous architecture can originate from the reaction of $\mathrm{K} / \mathrm{K}_{2} \mathrm{O}$ / $\mathrm{CO}_{2}$ with carbon materials. ${ }^{51}$ Meanwhile, the change tendency of the total pore volume with the increase of activation temperature and $\mathrm{KOH}$ concentration is in accord with the specific surface area. The total pore volume can be found going from $0.868 \mathrm{~cm}^{3} \mathrm{~g}^{-1}$ for NLDPC-700-4-2 to $1.374 \mathrm{~cm}^{3} \mathrm{~g}^{-1}$ for NLDPC-800-4-2 and $1.216 \mathrm{~cm}^{3} \mathrm{~g}^{-1}$ for NLDPC-900-4-2, and from $0.986 \mathrm{~cm}^{3} \mathrm{~g}^{-1}$ for NLDPC-800-4-1 to $1.152 \mathrm{~cm}^{3} \mathrm{~g}^{-1}$ for NLDPC800-4-3. As shown in Fig. 2d, the pore size distributions of NLDPCs also exhibit the existence of hierarchical porosity by combining micropores, mesopores, and macropores. The corresponding relative high amount of mesopores (40.27-68.06\%) can be a nice advantage to the fast transportation of electrolyte ions, which may be attributed for the improvement of the electrochemical performance. ${ }^{52}$ Such high specific surface area with a hierarchical porosity comprised of macro-, meso- and micro-pores as well as high total pore volume are beneficial for charge storage and rapid ion transportation, which make the asprepared NLDPCs have a great potential as electrode materials in LIBs and SCs application. ${ }^{\mathbf{8 , 1 5}}$

XPS analysis are adopted to probe the surface atom binding states of NLDPCs. As shown in the XPS spectrum (Fig. 3a), there are only C1s (peak position at $284.6 \mathrm{eV}$ ), N1s (peak position at $400 \mathrm{eV}$ ), and O1s (peak position at $533 \mathrm{eV}$ ) signals without other heteroatoms. Furthermore, the surface chemical composition of NLDPCs can also be reflected in Tables 1 and S2. $\dagger$ The NLDPCs are mainly composed of carbon (more than $78.21 \mathrm{wt} \%$ ) with nitrogen (less than $6.10 \mathrm{wt} \%$ ) and oxygen (less than 15.69 wt\%). Remarkably, as shown in Fig. 3c and d, the N-content of NLDPCs is very sensitive to the activation temperature, decreasing from $6.10 \mathrm{wt} \%$ for NLDPC-700-4-2 to $3.68 \mathrm{wt} \%$ for NLDPC-800-4-2 and 2.63 wt\% for NLDPC-900-4-2. Furthermore, the mass ratio of $\mathrm{KOH}$ to carbon precursor also effect the Ncontent of NLDPCs, decreasing from $4.50 \mathrm{wt} \%$ for NLDPC800-4-1 to 1.28 wt $\%$ for NLDPC-800-4-3. Importantly, the Ocontent demonstrates the same trend with that of the $\mathrm{N}$ content. In detail, the O-content decreases from $15.69 \mathrm{wt} \%$ for NLDPC-700-4-2 to $11.82 \mathrm{wt} \%$ for NLDPC-800-4-2 and $8.12 \mathrm{wt} \%$ for NLDPC-900-4-2, and from 14.74 $\mathrm{wt} \%$ for NLDPC-800-4-1 to $10.49 \mathrm{wt} \%$ for NLDPC-800-4-3. These results suggest that, with the increase of $\mathrm{KOH}$ mass loading or reaction temperature, unstable components in the carbon are more vulnerable to potassium in the process of activation, such as nitrogen and oxygen, which can decrease the content of $\mathrm{N}$ and $\mathrm{O} .{ }^{15}$ From the fitting result, the $\mathrm{C} 1 \mathrm{~s}$ spectra can be divided into four peaks of $\mathrm{C}=\mathrm{C} / \mathrm{C}-\mathrm{C}(284.6 \mathrm{eV}), \mathrm{C}-\mathrm{O} / \mathrm{C}-\mathrm{N}(285-286 \mathrm{eV}), \mathrm{C}=\mathrm{O}(286-287 \mathrm{eV})$ and $\mathrm{COOH}(289-290 \mathrm{eV}$ ) (as seen in Fig. $3 \mathrm{~b}$ and $\mathrm{S} 3 \dagger) .{ }^{53,54}$ From the fit of $\mathrm{O} 1 \mathrm{~s}$ spectra in Fig. $3 \mathrm{~h}$ and $\mathrm{S} 4, \dagger$ it can be found that there are three individual peaks centered at 531-532, 533-534, 534-536 eV, which correspond to $\mathrm{C}=\mathrm{O}$ quinone type groups $(\mathrm{O}-$ I), $\mathrm{C}-\mathrm{OH}$ phenol groups/C-O-C ether groups (O-II), and $\mathrm{COOH}$ carboxylic groups (O-III). ${ }^{55,56}$ For all NLDPC samples, the carbon-oxygen functional groups can improve the wettability of carbon materials further to enhance the faradaic reaction on the electrode/electrolyte surface for obtaining extra pseudocapacitance. ${ }^{\mathbf{1 3 , 2 4 , 5 7}}$ According to Fig. $3 \mathrm{e}$ and $\mathrm{S5,} \uparrow$ the high- resolution $\mathrm{N}$ 1s spectrum of NLDPCs can be spilt into four characteristic peaks, which are attributed to pyridinic-N (N-6, located at $398.0 \mathrm{eV})$, pyrrolic- $\mathrm{N}(\mathrm{N}-5$, located at $400.0 \mathrm{eV})$, quaternary- $\mathrm{N}(\mathrm{N}-\mathrm{Q}$, located at $401.0 \mathrm{eV})$ and oxidized $\mathrm{N}(\mathrm{N}-\mathrm{X}$, located at $403.0 \mathrm{eV}) .{ }^{\mathbf{4 4 , 5 8}}$ Furthermore, the component of the $\mathrm{N}$ functional groups can be tailed by reaction temperature and $\mathrm{KOH}$ mass loading, and the corresponding change of the relative nitrogen content can be seen in Fig. $3 \mathrm{f}$ and g. For the NLDPCs, the relative amounts of N-6 and N-5 tend to decrease as reaction temperature or the amount of $\mathrm{KOH}$ mass loading increasing. In contrast, the relative amounts of $\mathrm{N}-\mathrm{Q}$ and $\mathrm{N}-\mathrm{X}$ basically increase. The absolute concentrations of nitrogen species of the samples are shown in the Table S3. $\dagger$ It can be seen that the amounts of N-6 and N-5 decrease drastically, while the $\mathrm{N}-\mathrm{Q}$ and $\mathrm{N}-\mathrm{X}$ slowly reduce or barely change with the increase of reaction temperature and $\mathrm{KOH}$ loading. Therefore, these observations may result from that, the amounts of N-6 and N-5 preferentially eliminated, while the amount of $\mathrm{N}-\mathrm{Q}$ and $\mathrm{N}-\mathrm{X}$ have relatively better stability when the reaction temperature and $\mathrm{KOH}$ loading are increased. ${ }^{\mathbf{2 4 , 5 6 , 5 9}}$ The presence of $\mathrm{N}$ functional groups in samples is of great significance. Due to changing the electron distribution, $\mathrm{N}-6$ and $\mathrm{N}-5$ could facilitate the faradaic reaction-based pseudocapacitance. Moreover, the presence of $\mathrm{N}-\mathrm{Q}$ and $\mathrm{N}-\mathrm{X}$ can ameliorate the conductivity of electrode materials, which is attributed to enhance the rate and cycling performance..$^{55,56}$ The $\mathrm{N}$ and $\mathrm{O}$ atoms in carbon framework can change the energy band structure of carbon atoms. Besides, the pyridinic nitrogen, pyrrolic nitrogen and quinone oxygen presumably are confirmed to have the most pronounced influence on improving the electrochemical performance due to the occurred pseudocapacitive contributions. ${ }^{56,60,61}$ For further investigating the element composition of the sample, elemental analysis was employed through a conventional combustion method (Table 1). The nitrogen content of the NLDPCs measured by elemental analysis is slightly lower than that calculated by XPS analysis, suggesting nitrogen functional groups prefer to locate on the surface of the carbon matrix. In addition, the contents of nitrogen and oxygen tested by the elemental analysis demonstrates the same trend with XPS results as the $\mathrm{KOH}$ mass loading or reaction temperature increases.

\subsection{Electrochemical evaluation of NLDPC electrodes for supercapacitors}

The nettle leaf derived porous carbons, which possess high surface area, high amount of $\mathrm{N}$ and $\mathrm{O}$ doping, and hierarchical porosity, are beneficial to be a suitable electrode for SCs. The demonstration experiments were conducted in a coin cell, using a two-electrode system. Owing to the features of good fireresistance, preferable thermostability, and relative high operating voltage (3-4 V), EMIM-BF 4 was employed as electrolyte to promote the energy density of SCs. CV analysis was performed to characterize the electrochemical properties of NLDPCs. Fig. S6† exhibits the CV curves of NLDPCS at different sweep rates, and all $\mathrm{CV}$ curves demonstrate almost quasi-rectangular shapes, which indicate that the electric double layer 

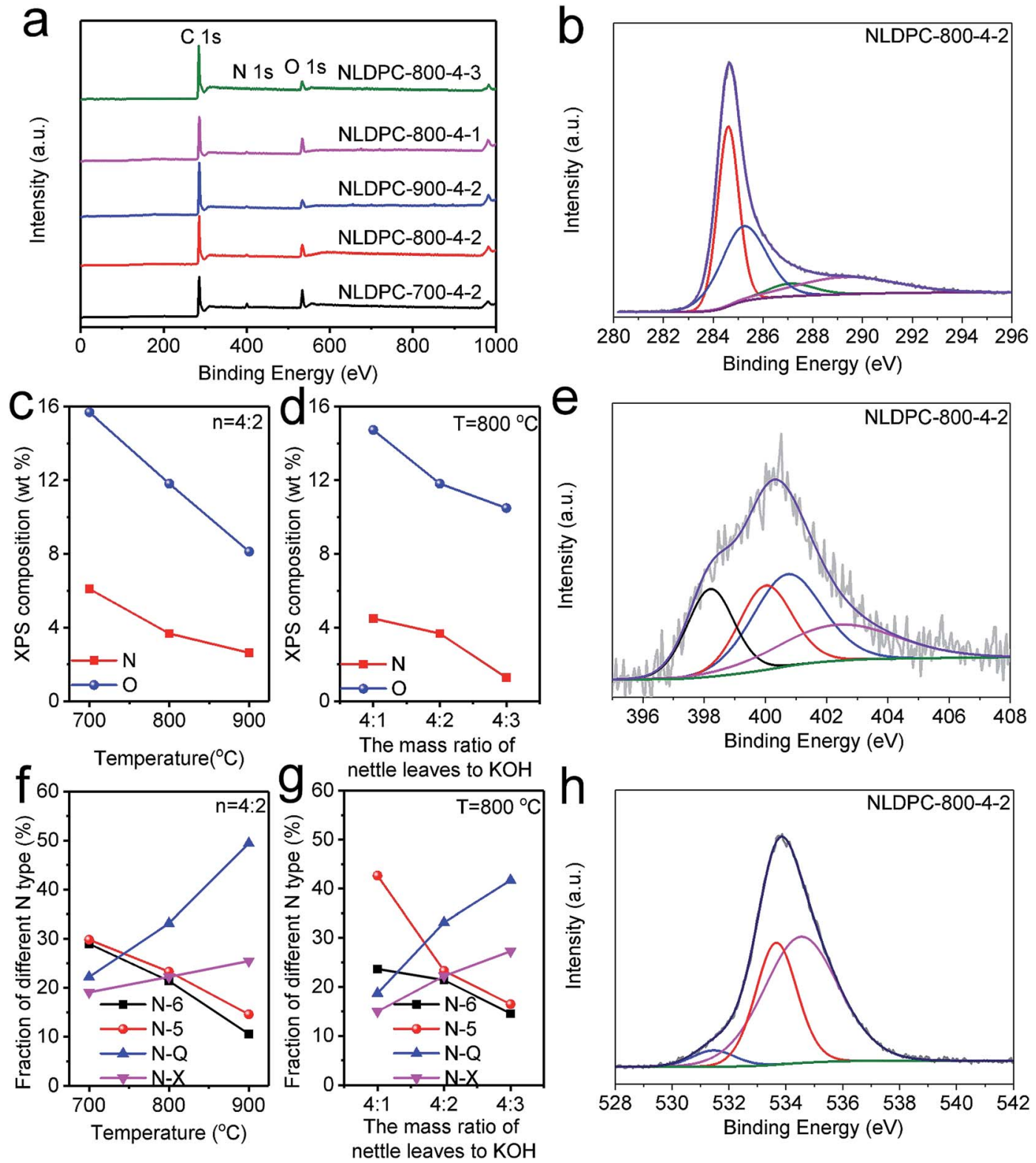

Fig. 3 (a) XPS survey spectra of NLDPC samples. (b) C 1s XPS spectra of the NLDPC-800-4-2 sample. (c) N and O contents of the NLDPC samples prepared at different temperatures with the same nettle leaves to $\mathrm{KOH}$ mass ratio. (d) N and O contents of the NLDPC samples prepared at different nettle leaves to $\mathrm{KOH}$ mass ratio with the same temperature. (e) N 1s XPS spectra of the NLDPC-800-4-2 sample. (f) Ratios of the different $\mathrm{N}$ types in the NLDPC samples at different nettle leaves to $\mathrm{KOH}$ mass ratio with the same temperature. (g) Ratios of the different $\mathrm{N}$ types in the NLDPC samples at different temperatures with the same nettle leaves to KOH mass ratio. (h) O 1s XPS spectra of the NLDPC-800-4-2 sample.

capacitance (EDLC) is dominant. ${ }^{42}$ However, the weakly broadened humps found in the CV curves at a low scan rate can be attributed to the nitrogen/oxygen functionalities undergoing faradaic reaction. ${ }^{60}$ Although the specific reactions mechanism and involved faradaic reaction have not been clearly studied in ionic liquid, we speculate that the reversible faradaic reactions between $\mathrm{O}-\mathrm{I} / \mathrm{N}-6 / \mathrm{N}-5$ functional groups and ionic liquid may be occurred, similar to that in the in aqueous solution. ${ }^{56,62-65}$ As the sweep rate increased to $500 \mathrm{mV} \mathrm{s}^{-1}$, the disappearance of weakly broadened humps and the negligible changed rectangular-like shape of CV curves, illustrating the smooth ion transport in the high viscosity electrolyte and the fast formation of EDLC. ${ }^{\mathbf{8}}$ Fig. 4a compares the CV curves of all NLDPCs at $10 \mathrm{mV} \mathrm{s}^{-1}$ tested at room temperature. Compared with NLDPC-800-4-2, NLDPC-900-4-2 and NLDPC-800-4-1 exhibit the lowest integrated area, which may result from the low specific surface area for NLDPC-800-4-1 and the lower content of nitrogen/oxygen for NLDPC-900-4-2. Moreover, NLDPC-800-4-1 and NLDPC-900-4-2 have relative low volume of micropores, and the charge accumulation in micropores can be hindered. It is worth to note that the NLDPC-800-4-2 with high surface area and moderate amount of nitrogen/oxygen containing groups show obvious 

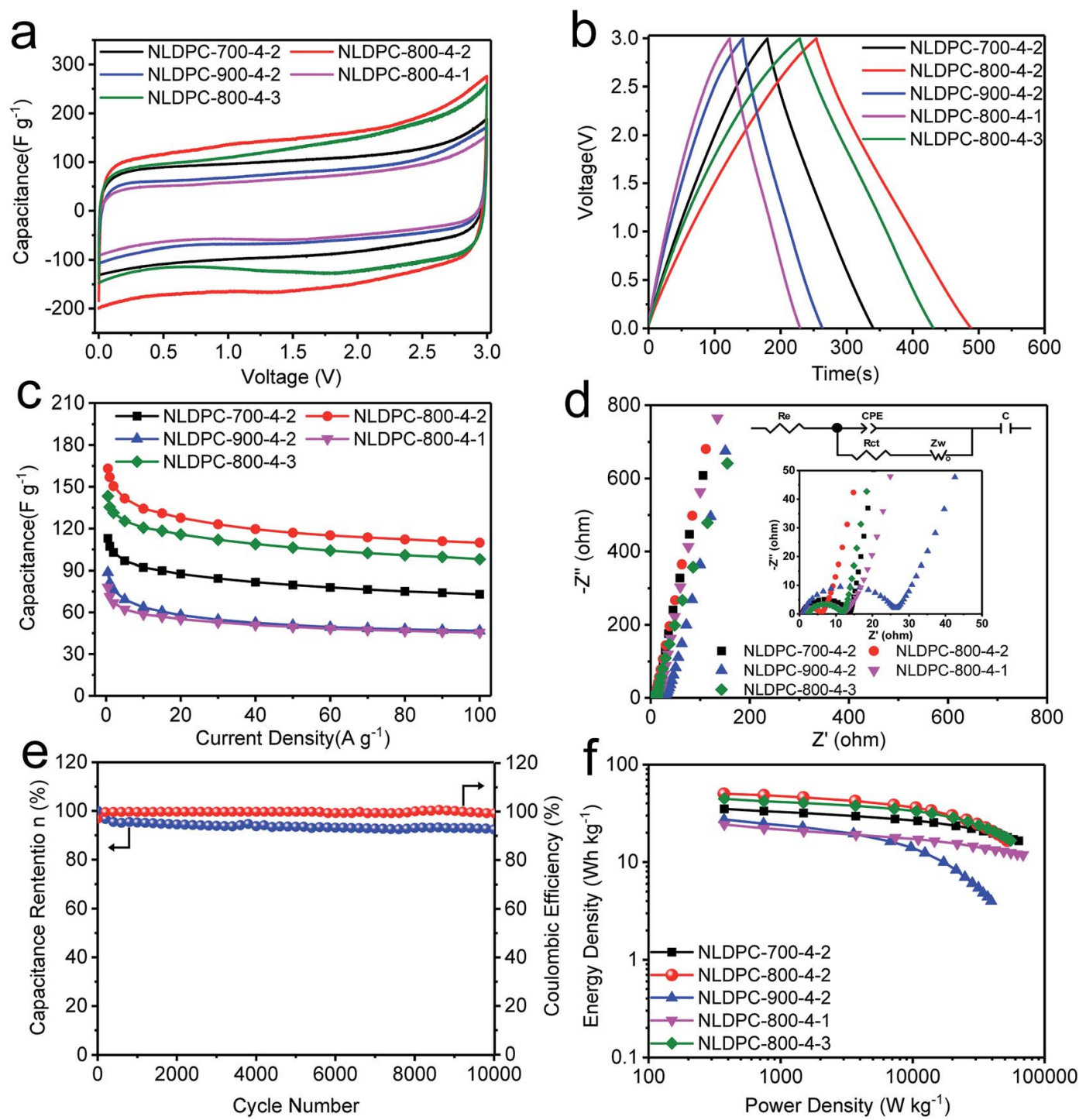

Fig. 4 Electrochemical performance of NLDPC electrodes for supercapacitors: (a) CV curves of NLDPC electrodes at $10 \mathrm{mV} \mathrm{s}^{-1}$. (b) Galvanostatic charge-discharge profiles of NLDPC electrodes at $1 \mathrm{~A} \mathrm{~g}^{-1}$. (c) Specific capacitance at various current densities for NLDPC electrodes. (d) Nyquist plots of NLDPC electrodes. (e) Cycling stability of NLDPC-800-4-2 tested at $10 \mathrm{~A} \mathrm{~g}^{-1}$ for 10000 cycles. (f) Ragone plot of NLDPC electrodes.

less distorted CV curves and higher CV loop than that other NLDPCs samples, intimating that the high surface area can offer abundant active sites for more EDLC and the nitrogen/ oxygen functional groups in the carbon structure can emphasize pseudocapacitance by faradaic reaction.

For characterizing the superior capacitive behavior of NLDPC-based SCs in practical applications, the analysis of galvanostatic charge-discharge was conducted from $0.5 \mathrm{~A} \mathrm{~g}^{-1}$ to $100 \mathrm{~A} \mathrm{~g}^{-1}$. Fig. $4 \mathrm{~b}$ and $\mathrm{S} 7 \dagger$ show the GCD curves of NLDPCs samples at $1 \mathrm{~A} \mathrm{~g}^{-1}, 20 \mathrm{~A} \mathrm{~g}^{-1}$, and $50 \mathrm{~A} \mathrm{~g}^{-1}$. Furthermore, the GCD curves maintain a quasi-triangular and symmetrical sharp at each current density, suggesting that NLDPCs possess ideal EDLC behavior and excellent coulombic efficiency, which is in agreement with the analysis of $\mathrm{CV}$ characterization. ${ }^{66}$ It should be noted that the IR loss cannot be observed from the GCD curves at $1 \mathrm{~A} \mathrm{~g}^{-1}$, which indicates the rapid ion diffusion in
NLDPCs. However, the IR drop of NLDPCs become higher with the increase of testing current density, which result from the inefficiency of ion transfer rate at high current density. ${ }^{40}$ It can be observed that NLDPC-900-4-2 exhibit the highest IR drop, which may be related with its porous structure, leading to a high resistance for the ion diffusion. ${ }^{8}$

The function relation between current density and specific capacitance of the NLDPC samples is plotted in Fig. 4c. As generally accepted, the resistance of ions transportation in electrolyte, which caused by the nanopores of carbon materials, result in the reduced specific capacitance with the raise of current density. The gravimetric capacitances of 113, 163, 89, 78 and $143 \mathrm{~F} \mathrm{~g}^{-1}$ are obtained for NLDPC-700-4-2, NLDPC-800-4-2, NLDPC-900-4-2, NLDPC-800-4-1 and NLDPC-800-4-3 at $0.5 \mathrm{~A} \mathrm{~g}^{-1}$, respectively. Besides, the measured packing densities of NLDPC-700-4-2, NLDPC-800-4-2, NLDPC-900-4-2, NLDPC- 
800-4-1 and NLDPC-800-4-3 are 0.68, 0.60, 0.56, 0.75 and $0.51 \mathrm{~g} \mathrm{~cm}^{-3}$. Consequently, the corresponding volumetric capacitances are $77,98,50,59$ and $73 \mathrm{~F} \mathrm{~cm}^{-3}$. It can be seen that NLDPC-800-4-2 electrode offers the best gravimetric capacitance of $163 \mathrm{~F} \mathrm{~g}^{-1}$ and volumetric capacitance of $98 \mathrm{~F} \mathrm{~cm}^{-3}$. When the current density increases up to $100 \mathrm{~A} \mathrm{~g}^{-1}$, NLDPC-800-4-2 also possesses the high specific capacitance of $110 \mathrm{~F} \mathrm{~g}^{-1}\left(66 \mathrm{~F} \mathrm{~cm}^{-3}\right)$ with extremely high capacitance retention ratio of $68 \%$. The highest specific surface area with abundant active site, and hierarchical porosity with smooth ion-transport pathway could be the main reasons for the superior rate performance of NLDPC-800-4-2 sample. As shown in Table S4, $\dagger$ it is worth nothing that the specific capacitance and corresponding capacitance retention of NLDPCs are expected to be competitive compared with the reported carbon materials. Based on BET surface area, the value of specific surface area-normalized capacitance calculated at $1 \mathrm{~A} \mathrm{~g}^{-1}$ is $7.8 \mu \mathrm{F} \mathrm{cm} \mathrm{cm}^{-2}$ for NLDPC700-4-2, 8.0 $\mu \mathrm{F} \mathrm{cm} \mathrm{cm}^{-2}$ for NLDPC-800-4-2, $6.0 \mu \mathrm{F} \mathrm{cm} \mathrm{cm}^{-2}$ for NLDPC-900-4-2, $6.7 \mu \mathrm{F} \mathrm{cm}{ }^{-2}$ for NLDPC-800-4-1 and 9.0 $\mu \mathrm{F}$ $\mathrm{cm}^{-2}$ for NLDPC-800-4-3. The NLDPC-800-4-2 and NLDPC-8004-1 achieve the higher specific surface area normalized capacitance, which are quite competitive to that of reported advanced carbon materials (such as activated carbons $\left(4.4 \mu \mathrm{F} \mathrm{cm}{ }^{-2}\right){ }^{13}$ activated graphene $\left(6.9 \mu \mathrm{F} \mathrm{cm}{ }^{-2}\right),{ }^{66}$ mesoporous carbons $(7.3 \mu \mathrm{F}$ $\left.\left.\mathrm{cm}^{-2}\right)^{67}\right)$. The high surface area normalized capacitance of NLDPCs imply a good size matching between nanopores and electrolyte-ions.

The EIS method was further chosen to probe into the process of electron/ion transport for NLDPC electrodes. From the fitting spectrum (as shown in Fig. 4d), at low frequency range, Nyquist plot of each electrode displays a quasi-vertical line, demonstrating the relative low Warburg impedance and fast ion diffusion rate. ${ }^{68}$ At middle-high frequency region, the semicircles express the message of charge transfer resistance $\left(R_{\mathrm{ct}}\right)$, which is calculated to be $12.4 \Omega$ for NLDPC-700-4-2, $4.9 \Omega$ for NLDPC-8004-2, $24.7 \Omega$ for NLDPC-900-4-2, $9.1 \Omega$ for NLDPC-800-4-1, and 9.6 $\Omega$ for NLDPC-800-4-3. Among the above values, the NLDPC-800-42 sample possesses the smallest $R_{\mathrm{ct}}$ on account of its most smooth diffusion channel for the adsorption/desorption of electrolyte-ions. At high frequency range, the equivalent series resistance $\left(R_{\mathrm{e}}\right)$ contained the resistance of carbon material and electrolyte and contact resistance between the carbon material and current collector, ${ }^{48,69}$ is calculated to be in the range of $0.8^{-}$ $2.5 \Omega$. The relative low $R_{\mathrm{e}}$ indicates high conductivity in ionic liquid electrolyte. ${ }^{18}$ It can be concluded that the high surface area with hierarchical porous structure can shorten ion transportation distance as well as offer more effective electrode/electrolyte interfaces further to facilitate the transfer rate of ion/charge during the electrochemical process, result in the incremental capacitive performance. For evaluating the cycle stability, the cycle life test of NLDPC-800-4-2 was conducted at $10 \mathrm{~A} \mathrm{~g}^{-1}$ (Fig. 4e). It is worth to emphasize that only $8 \%$ loss of its initial capacitance is found over 10000 cycles, which can confirm the excellent cycle stability.

Fig. $4 \mathrm{f}$ exhibits the Ragone plots of all NLDPC- $T$ - $n$ electrodes on the basis of total electrode mass in a two-electrode system. More importantly, the NLDPC samples assembled SCs provide a specific energy of $35 \mathrm{~W} \mathrm{~h} \mathrm{~kg}^{-1}$ (NLDPC-700-4-2), $50 \mathrm{~W} \mathrm{~h} \mathrm{~kg}$ (NLDPC-800-4-2), $27 \mathrm{~W} \mathrm{~h} \mathrm{~kg}{ }^{-1}$ (NLDPC-900-4-2), $24 \mathrm{~W} \mathrm{~h} \mathrm{~kg}$ (NLDPC-800-4-1), and $44 \mathrm{~W} \mathrm{~h} \mathrm{~kg}^{-1}$ (NLDPC-800-4-3) at a specific power of $372-374 \mathrm{~W} \mathrm{~kg}^{-1}$. With the power increasing to $40 \mathrm{~kW}$ $\mathrm{kg}^{-1}$, a specific energy of $21 \mathrm{~W} \mathrm{~h} \mathrm{~kg}^{-1}$ for NLDPC-800-4-2 sample can be achieved. Even though the actual demand allows the device charged in $2 \mathrm{~s}$, the NLDPC-800-4-2 sample can still obtain a specific energy as high as $17 \mathrm{~W} \mathrm{~h} \mathrm{~kg}^{-1}$, indicating the superior rate capability. The energy-power characteristics for NLDPCs is competitive or superior to investigated carbon-based and ionic liquid-based SCs (Table S4 $\dagger$ ).

\subsection{Electrochemical evaluation of NLDPCs for lithium ion batteries}

The nettle leaf derived porous carbons were also employed as anodes materials for LIB in half-cell configurations with a counter electrode of Li metal foil. And the LIB performance was first tested within the voltage of $0.01-3.0 \mathrm{~V}$ by $\mathrm{CV}$ measurement at a sweep rate of $0.1 \mathrm{mV} \mathrm{s}^{-1}$. Fig. $5 \mathrm{a}$ and $\mathrm{S} 8 \dagger$ display the CV profiles of the NLDPC anodes from first to fifth cycle. It can be seen that a notable cathodic peak presents between 0.01 and $1.0 \mathrm{~V}$ in the initial cycle as well as between 0.01 and $0.5 \mathrm{~V}$ in the subsequent cycles. It can be seen that the mentioned cathodic peak in the 1st CV loop show much higher intensity than that of the rest, which could be attributed to the electrolyte decomposition, the formation of solid electrolyte interphase layer (SEI), and the irreversible insertion of $\mathrm{Li}^{+}$into special sites of carbon material. ${ }^{13,70}$ In the later cycles, the CV loop almost overlaps on each other, illustrating the outstanding reversibility of NLDPC electrodes for $\mathrm{Li}^{+}$insertion/adsorption and extraction/desorption. A capacitive behavior of Li storage can be found by the minor redox humps and the "box-like" CV loops from 0.5 to $3.0 \mathrm{~V}$, resulting from the $\mathrm{Li}^{+}$physisorption by the electric double layer and reversible chemisorption on defect and edge sites by the heteroatom doping. ${ }^{71}$

The galvanostatic discharge/charge profiles of NLDPC anodes were measured for $1 \mathrm{st}, 2 \mathrm{nd}, 5 \mathrm{th}$, and 10 th cycles at $0.1 \mathrm{~A} \mathrm{~g}^{-1}$ between the potential of $0.01-3.0 \mathrm{~V}$ (as shown in Fig. $5 \mathrm{~b}$ and $\mathrm{S} 9 \dagger)$. For the 1 st discharge curve of NLDPCs, a slight potential plateau slope appears from 1.0 to $0.3 \mathrm{~V}$ owing to the SEI formation. Meanwhile, the smooth potential plateau below $0.3 \mathrm{~V}$ is caused by the $\mathrm{Li}^{+}$intercalation among the graphitic layers. ${ }^{6,66}$ The NLDPC-700-4-2 and NLDPC-800-4-1 exhibit relative low reversible charge capacities of 891 and $827 \mathrm{~mA} \mathrm{~h} \mathrm{~g}^{-1}$ for the first cycle, which can be caused by their low specific surface area. Moreover, the high heteroatom doping for NLDPC-700-4-2 and NLDPC-800-4-1 can result in more defects, leading to large irreversible capacity. However, NLDPC-800-4-2 demonstrates a high initial reversible charging capacity of $1262 \mathrm{~mA} \mathrm{~h} \mathrm{~g}{ }^{-1}$, about 2.5 times greater than the theoretical capacity of graphite $\left(372 \mathrm{~mA} \mathrm{~h} \mathrm{~g}^{-1}\right)$. Compared with the capacity of graphite from intercalation, the high capacity of NLDPC-800-4-2 can be realized by the physi/chemisorption of lithium ions on the surface, defective and active sites, and functional groups, and the lithium intercalation between the graphitic layers. The highest specific surface area with hierarchical porosity for NLDPC-800- 

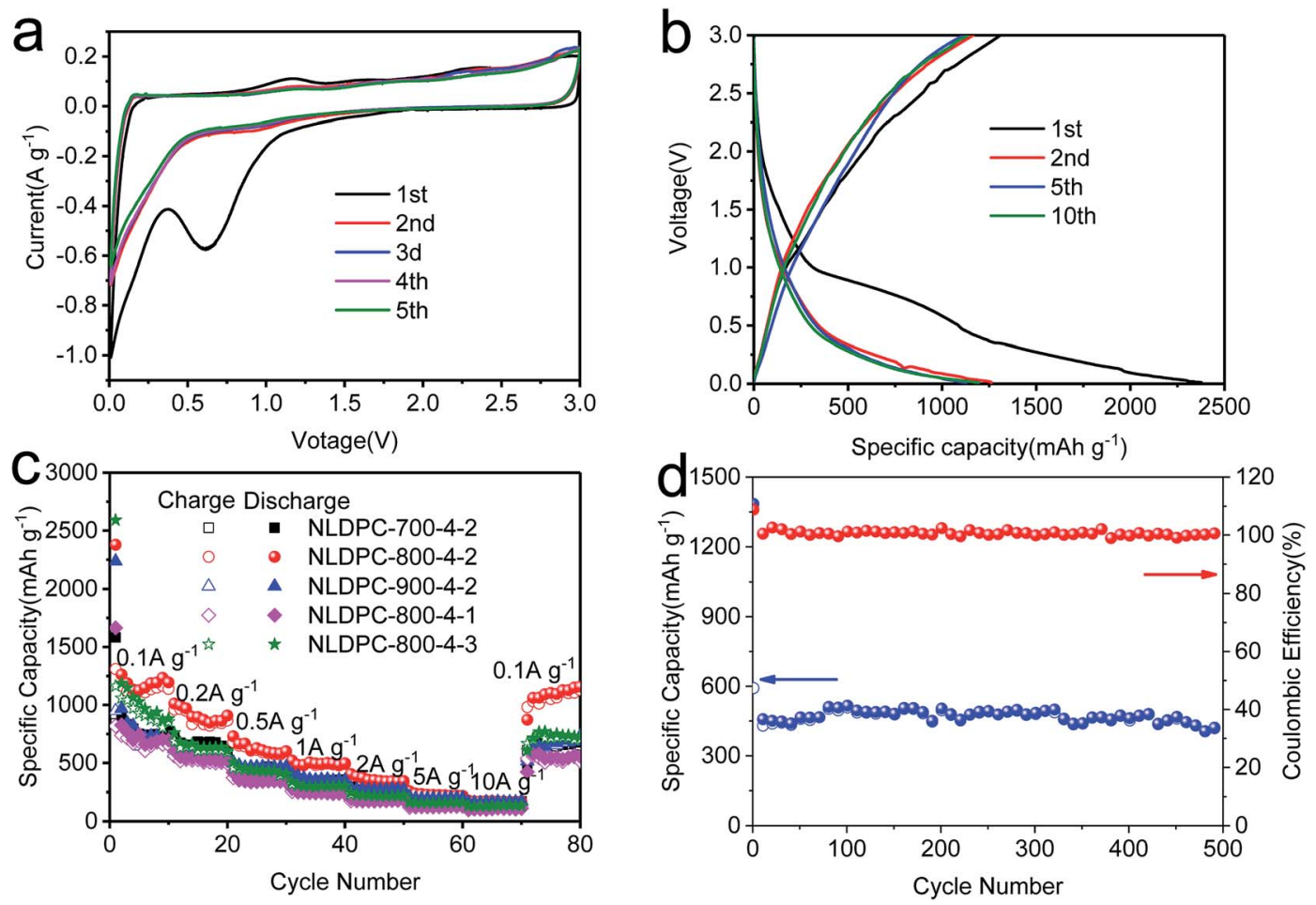

Fig. 5 Electrochemical performance of NLDPC anodes for lithium-ion batteries: (a) CV curves of NLDPC-800-4-2 at 0.1 mV s ${ }^{-1}$. (b) Chargedischarge curves of NLDPC-800-4-2 at $0.1 \mathrm{~A} \mathrm{~g}^{-1}$. (c) Rate capability at different current densities. (d) Cycling performance with the related coulombic efficiency for NLDPC-800-4-2, tested at a current density of $1 \mathrm{~A} \mathrm{~g}^{-1}$.

4-2 can facilitate the insertion/extraction of $\mathrm{Li}^{+}$in the carbon structure as well as the adsorption/desorption of $\mathrm{Li}^{+}$on the surface, heteroatomic functional groups, and defective sites, which contribute to enhance the lithium storage capacity. The initial reversible capacity is 969 and $1187 \mathrm{~mA} \mathrm{~h} \mathrm{~g}^{-1}$ for NLDPC900-4-2 and NLDPC-800-4-3. Compared with NLDPC-800-4-2, the decreased capacity for NLDPC-900-4-2 and NLDPC-800-4-3 can be ascribed to the irreversible trapping of $\mathrm{Li}^{+}$within the defective structures. ${ }^{72}$ In addition, the initial coulombic efficiency (ICE) of NLDPC-700-4-2, NLDPC-800-4-2, NLDPC-900-4-2, NLDPC-800-4-1 and NLDPC-800-4-3 are 53.1\%, 55.1\%, 42.5\%, $49.2 \%, 44.9 \%$ at $0.1 \mathrm{~A} \mathrm{~g}^{-1}$. NLDPC-900-4-2 and NLDPC-800-4-3 with more defects under high activation temperature and $\mathrm{KOH}$ loading exhibit low ICE value. It is widely accepted that the relatively low CE would result from the combination of SEI formation on the large surface area and irreversible trapping at defect sites. However, it can be found that, though NLDPC-8004-2 processes the highest surface area, it demonstrates the largest ICE, which indicates that tuning the content of heteroatom doping, and/or graphitization levels are effective for improving the ICE values.

To further confirm the performance of the nettle leaf derived porous carbons suitable for high rate applications, the rate capacities of NLDPC anodes were evaluated by employing charge/discharge cycles at various current densities (Fig. 5c). All NLDPC samples are cycled for 10 cycles with the discharge/ charge rates increased stepwise from $0.5 \mathrm{~A} \mathrm{~g}^{-1}$ to $10 \mathrm{~A} \mathrm{~g}^{-1}$. When tested at $0.5 \mathrm{~A} \mathrm{~g}^{-1}$, NLDPC-800-4-2 exhibits a high reversible capacity of $730 \mathrm{~mA} \mathrm{~h} \mathrm{~g}{ }^{-1}$, and the half-cell can be charged within one hour. Even though the current density increases to 5 and $10 \mathrm{~A} \mathrm{~g}^{-1}$, the NLDPC-800-4-2 can still obtain the reversible capacity of 256 and $178 \mathrm{~mA} \mathrm{~h} \mathrm{~g}^{-1}$, respectively (charged within a few minutes). Besides, when turning back to $0.1 \mathrm{~A} \mathrm{~g}^{-1}$, the reversible capacity of NLDPC-800-4-2 still can recover to $1159 \mathrm{~mA} \mathrm{~h} \mathrm{~g}{ }^{-1}$, which indicates the superior reversibility. In addition, after evaluating the electrochemical properties of Super P (Fig. S10a†), we have calculated the real capacity of NLDPCs samples, which was shown in Fig. S10b. $\dagger$ More specifically, as exhibited in Fig. S10c, $\uparrow$ the NLDPC-800-4-2 sample demonstrates the true capacity of $1211 \mathrm{~mA} \mathrm{~h} \mathrm{~g}^{-1}$ at $0.1 \mathrm{~A} \mathrm{~g}^{-1}$ and $158 \mathrm{~mA} \mathrm{~h} \mathrm{~g}^{-1}$ at $10 \mathrm{~A} \mathrm{~g}^{-1}$, which indicates that the contribution of Super $\mathrm{P}$ to the total capacity is very small.

The N, O co-doped nettle leaf derived porous carbon anode also exhibits outstanding cycling stability. As shown in Fig. 5d, the capacity of NLDPC-800-4-2 is maintained at $439 \mathrm{~mA} \mathrm{~h} \mathrm{~g}^{-1}$ over 500 cycles with negligible capacity fading, demonstrating the potential of this carbon anode for practical application. Besides, this anode shows coulombic efficiency closed to $100 \%$ during cycling. The EIS test is also used to understand the electrochemical behavior before cycling and after 500 cycles (Fig. S11†). The Nyquist plot exhibits a semicircle with a small diameter at high frequency region before cycling corresponding to the charge-transfer resistance $\left(R_{\mathrm{ct}}\right)$. Upon cycling, the emergence of two depressed semicircles at medium-high frequency region suggest a new resistance formation $\left(R_{\mathrm{f}}\right)$ which can be attributed to the SEI formation and lithium ion transport across 
the SEI layer. ${ }^{\mathbf{8}, 54,70}$ From the fitting results with the equivalent circuit model, the value of $R_{\mathrm{f}}$ is $18.6 \Omega$ after cycling, which can impede the ion diffusion. Moreover, the equivalent series resistance $\left(R_{\mathrm{e}}\right)$ after 500 cycles $(9.9 \Omega)$ is higher than before cycling $(4.2 \Omega)$. This results can be ascribed to the SEI growth and electrode materials disintegration. It should be noted that the value of $R_{\mathrm{ct}}$ is $\mathbf{1 4 . 5} \Omega$ after cycling, which is a little higher than the $R_{\mathrm{ct}}(11.2 \Omega)$ before cycling, which is attributed to maintain superior cycling stability. Compared with the reported carbon materials as electrodes for LIBs in $\mathrm{LiPF}_{6}$ (Table S5 $\dagger$ ), the NLDPC samples exhibit superior rate performance, favorable charge capacity and excellent cycling stability, which can be employed as electrode materials for advanced LIBs.

For further understand kinetics behavior of lithium storage, we have employed the CV curves measured at different scan rates from 0.2 to $1 \mathrm{mV} \mathrm{s}^{-1}$, as shown in the Fig. $6 \mathrm{a}$ and $\mathrm{S} 12 \mathrm{a}-\mathrm{d} . \dagger$ The relationship between the current and scan rate can be characterized by the following equation:

$$
i=a \nu^{b}
$$

where $i$ and $\nu$ represents the current and scan rate respectively, and $a$ and $b$ are variables. Plotting the logarithm of the current and the scanning rate, the value of $b$ can be obtained according to the slope of the linear relationship between them. ${ }^{73}$ When $b=$
1 , this means that capacitive controlled dominates the process. When $b=0.5$, diffusion-controlled process is dominated.$^{47}$ The $b$ value for cathodic and anodic of the NLDPCs are 0.82-0.85 and $0.65-0.69$, which indicates that the kinetics process is dominated by capacitive-controlled (Fig. $6 \mathrm{~b}$ and S13a-d $\dagger$ ). More specifically, the proportion of capacitive behavior in the current response can be quantitatively assessed by the following equation:

$$
i=k_{1} \nu+k_{2} \nu^{1 / 2}
$$

or

$$
i / \nu^{1 / 2}=k_{1} \nu^{1 / 2}+k_{2}
$$

where $k_{1}$ and $k_{2}$ are the variables. We can obtained the contribution of capacitive behavior by linear fitting the curves of $i / \nu^{1 / 2}-\nu^{1 / 2}$ at a fixed potential with different scan rates. ${ }^{47,73}$ As exhibited in the Fig. $6 \mathrm{c}$ and S14a-e, $\dagger$ the capacitive behavior accounted for the proportion in the current response are $56.9 \%, 55.7 \%, 51.0 \%, 51.4 \%, 45.4 \%$ for NLDPC700-4-2, NLDPC-800-4-2, NLDPC-900-4-2, NLDPC-800-4-1 and NLDPC-800-4-3 at the scan rate of $1 \mathrm{mV} \mathrm{s}^{-1}$. Besides, the proportion of capacitive behavior in the current response increases gradually as the scanning rate increases. The high
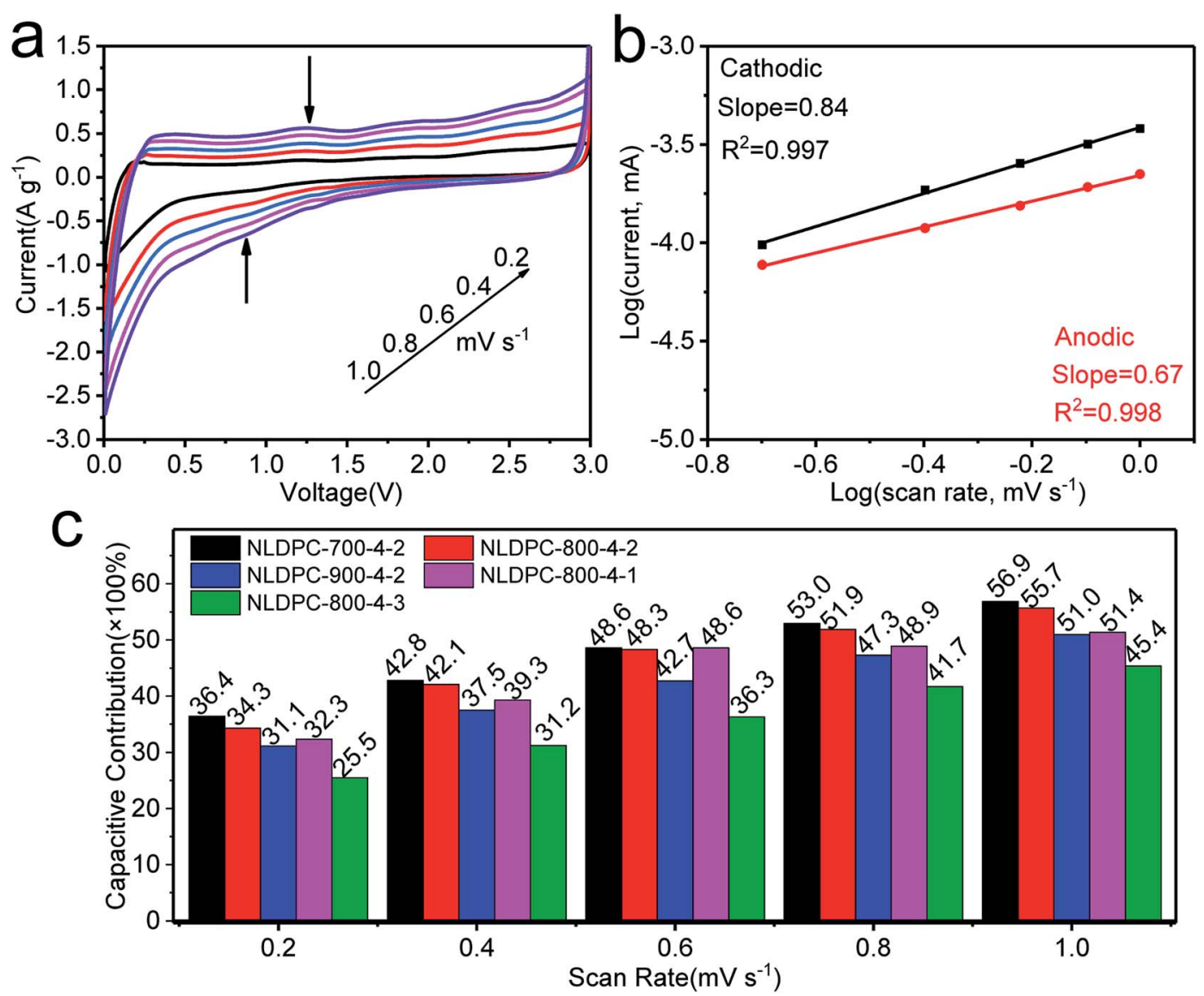

Fig. 6 (a) CV curves at different scan rates of NLDPC-800-4-2. (b) Selected cathodic and anodic $b$ values of peak currents (as indicated in (a)) for NLDPC-800-4-2. (c) Normalized contribution ratio of capacitive capacities at different scan rates for NLDPCs. 
proportion of capacitive contribution of NLDPCs can result from the synergistic effect of high surface area, the hierarchical porosity and the abundant nitrogen and oxygen functional groups. As a result, such capacitive behaviors including physisorption/chemisorption have a very positive effect on improving rate performance.

To sum up, the electrochemical test results make clear that nettle leaf derived porous carbons are suitable as promising supercapacitor and lithium ion battery electrodes. The favorable electrochemical performance of NLDPCs can obtain a good explanation by several microstructural reasons. First, hierarchical porosity (micro-, meso-, and macropores) can provide short ion transport length as well as minimize the high-rate diffusional loss, leading to increased rate performance. Second, the 3D architecture with high surface area can ensure enough contact area and active sites between electrolyte and electrode for charge accumulation. Third, the rich defects and disorders can be modulated by heteroatom doping, which can offer extra pseudocapacitance by surface redox reactions. Based on the above-discussed factors and the synergy among them, nettle leaf derived porous carbons are beneficial for being used for next-generation energy storage systems.

\section{Conclusions}

Here, we have prepared nitrogen and oxygen co-doped carbon materials with high specific surface area and hierarchical porosity from the nettle leaves by using a facile carbonization/ activation method, and the as-obtained carbons demonstrate favorable performance as electrodes in both SCs and LIBs. The symmetric SCs can provide high specific capacitance of $163 \mathrm{~F}$ $\mathrm{g}^{-1}$ in EMIM $\mathrm{BF}_{4}$ electrolyte with capacitance retention ratio of $67.5 \%$ at the current density of $100 \mathrm{~A} \mathrm{~g}^{-1}$. Moreover, the SCs can deliver a high energy density of $50 \mathrm{~W} \mathrm{~h} \mathrm{~kg}^{-1}$ at room temperature. As LIBs anodes, the carbon electrode can achieve a reversible lithium charge capacity of $1262 \mathrm{~mA} \mathrm{~h} \mathrm{~g}^{-1}$ at $0.1 \mathrm{~A} \mathrm{~g}^{-1}$ and $730 \mathrm{~mA} \mathrm{~h} \mathrm{~g}^{-1}$ at $0.5 \mathrm{~A} \mathrm{~g}^{-1}$. The above superior electrochemical properties, in combination with the ecofriendly and cost-effective process for preparation, can make nettle leaf derived carbon as a potential electrode material for advanced energy storage systems.

\section{Conflicts of interest}

There are no conflicts to declare.

\section{Acknowledgements}

The authors are grateful for financial support from the Fundamental Research Funds for the Central Universities (No. 201822008 and 201941010), the Shandong Provincial Key R\&D Plan and the Public Welfare Special Program, China (2019GGX102038 and 2017GGX20124), the Qingdao City Programs for Science and Technology Plan Projects (19-6-2-77$\mathrm{cg}$ ), the National Natural Science Foundation of China (No. 21775142, 51602150, and 21471139), the Sino-German Center for Research Promotion (Grants GZ 1351), and the Natural Science Foundation of Jiangsu Province (No. BK20161005).

\section{Notes and references}

1 M. Armand and J. M. Tarascon, Nature, 2008, 451, 652-657. 2 P. G. Bruce, B. Scrosati and J. M. Tarascon, Angew. Chem., Int. Ed., 2008, 47, 2930-2946.

3 B. Xu, S. Yue, Z. Sui, X. Zhang, S. Hou, G. Cao and Y. Yang, Energy Environ. Sci., 2011, 4, 2826-2830.

4 Z. Lei, J. Zhang, L. L. Zhang, N. A. Kumar and X. S. Zhao, Energy Environ. Sci., 2016, 9, 1891-1930.

5 L. Qie, W. M. Chen, Z. H. Wang, Q. G. Shao, X. Li, L. X. Yuan, X. L. Hu, W. X. Zhang and Y. H. Huang, Adv. Mater., 2012, 24, 2047-2050.

6 P. Simon, Y. Gogotsi and B. Dunn, Science, 2014, 343, 12101211.

7 M. Armand and J.-M. Tarascon, Nature, 2008, 451, 652-657. 8 W. Huanlei, X. Zhanwei, K. Alireza, L. Zhi, C. Kai, T. Xuehai, S. Tyler James, C. K. King'Ondu, C. M. B. Holt and B. C. Olsen, ACS Nano, 2013, 7, 5131-5141.

9 H. D. Yoo, E. Markevich, G. Salitra, D. Sharon and D. Aurbach, Mater. Today, 2014, 17, 110-121.

10 N. A. Kaskhedikar and J. Maier, Adv. Mater., 2009, 21, 26642680.

11 P. Yu, Z. Zhang, L. Zheng, F. Teng, L. Hu and X. Fang, Adv. Energy Mater., 2016, 6, 1601111.

12 J. Niu, R. Shao, J. Liang, M. Dou, Z. Li, Y. Huang and F. Wang, Nano Energy, 2017, 36, 322-330.

13 W. Yu, H. Wang, S. Liu, N. Mao, X. Liu, J. Shi, W. Liu, S. Chen and X. Wang, J. Mater. Chem. A, 2016, 4, 5973-5983.

14 L. Yao, Q. Wu, P. Zhang, J. Zhang, D. Wang, Y. Li, X. Ren, H. Mi, L. Deng and Z. Zheng, Adv. Mater., 2018, 30, 1706054.

15 N. Mao, H. Wang, Y. Sui, Y. Cui, J. Pokrzywinski, J. Shi, W. Liu, S. Chen, X. Wang and D. Mitlin, Nano Res., 2017, 10, 1767-1783.

16 L. Qie, W. M. Chen, Z. H. Wang, Q. G. Shao, X. Li, L. X. Yuan, X. L. Hu, W. X. Zhang and Y. H. Huang, Adv. Mater., 2012, 24, 2047-2050.

17 K. Nomura, H. Nishihara, N. Kobayashi, T. Asada and T. Kyotani, Energy Environ. Sci., 2019, 12, 1542-1549.

18 Y. Cui, H. Wang, X. Xu, Y. Lv, J. Shi, W. Liu, S. Chen and X. Wang, Sustainable Energy Fuels, 2018, 2, 381-391.

19 F. Lai, G. Zhou, F. Li, Z. He, D. Yong, W. Bai, Y. Huang, W. W. Tjiu, Y.-E. Miao, B. Pan and T. Liu, ACS Sustainable Chem. Eng., 2018, 6, 3143-3153.

20 L. Kong, J. Zhu, W. Shuang and X.-H. Bu, Adv. Energy Mater., 2018, 8, 1801515.

21 Z. H. Huang, T. Y. Liu, Y. Song, Y. Li and X. X. Liu, Nanoscale, 2017, 9, 13119-13127.

22 Z. Zhichao and X. Yibing, J. Power Sources, 2018, 400, 264276.

23 J. Ou, L. Yang, Z. Zhang and X. Xi, J. Power Sources, 2016, 333, 193-202.

24 H. Zhang, M. Lu, H. Wang, Y. Lyu, D. Li, S. Sun, J. Shi and W. Liu, Sustainable Energy Fuels, 2018, 2, 2314-2324. 
25 X. Dong, H. Jin, R. Wang, J. Zhang, X. Feng, C. Yan, S. Chen, S. Wang, J. Wang and J. Lu, Adv. Energy Mater., 2018, 8, 1702695.

26 G. Zhao, C. Chen, D. Yu, L. Sun, C. Yang, H. Zhang, Y. Sun, F. Besenbacher and M. Yu, Nano Energy, 2018, 47, 547-555.

27 C. Lv, W. Xu, H. Liu, L. Zhang, S. Chen, X. Yang, X. Xu and D. Yang, Small, 2019, 15, 1900816.

28 P. Lu, Y. Sun, H. Xiang, X. Liang and Y. Yu, Adv. Energy Mater., 2018, 8, 1702434.

29 R. Thangavel, A. G. Kannan, R. Ponraj, V. Thangavel, D.-W. Kim and Y.-S. Lee, J. Mater. Chem. A, 2018, 6, 17751-17762.

30 Z. Wang, Y. Tan, Y. Yang, X. Zhao, Y. Liu, L. Niu, B. Tichnell, L. Kong, L. Kang, Z. Liu and F. Ran, J. Power Sources, 2018, 378, 499-510.

31 E. Hao, W. Liu, S. Liu, Y. Zhang, H. Wang, S. Chen, F. Cheng, S. Zhao and H. Yang, J. Mater. Chem. A, 2017, 5, 2204-2214.

32 X. Zhou, F. Chen, T. Bai, B. Long, Q. Liao, Y. Ren and J. Yang, Green Chem., 2016, 18, 2078-2088.

33 G. Ye, X. Zhu, S. Chen, D. Li, Y. Yin, Y. Lu, S. Komarneni and D. Yang, J. Mater. Chem. A, 2017, 5, 8247-8254.

34 J. Ding, H. Wang, Z. Li, A. Kohandehghan, K. Cui, Z. Xu, B. Zahiri, X. Tan, E. M. Lotfabad and B. C. Olsen, ACS Nano, 2013, 7, 11004-11015.

35 L. Wang, Z. Schnepp and M. M. Titirici, J. Mater. Chem. A, 2013, 1, 5269-5273.

36 C. Zhu and T. Akiyama, Green Chem., 2016, 18, 2106-2114.

37 J. Hao, Y. Wang, C. Chi, J. Wang, Q. Guo, Y. Yang, Y. Li, X. Liu and J. Zhao, Sustainable Energy Fuels, 2018, 2, 2358-2365.

38 Z. Bi, Q.-Q. Kong, Y. Cao, G. S. G. Sun, F. Su, X.-X. Wei, X.-M. Li, A. Ahmad, L. Xie and C.-M. Chen, J. Mater. Chem. A, 2019, 7, 16028-16045.

39 W. Qian, F. Sun, Y. Xu, L. Qiu, C. Liu, S. Wang and F. Yan, Energy Environ. Sci., 2014, 7, 379-386.

40 D. W. Wang, F. Li, M. Liu, G. Q. Lu and H. M. Cheng, Angew. Chem., Int. Ed., 2008, 47, 373-376.

41 G. Qu, S. Jia, H. Wang, F. Cao, L. Li, C. Qing, D. Sun, B. Wang, Y. Tang and J. Wang, ACS Appl. Mater. Interfaces, 2016, 8, 20822-20830.

42 Y. Cui, H. Wang, N. Mao, W. Yu, J. Shi, M. Huang, W. Liu, S. Chen and X. Wang, J. Power Sources, 2017, 361, 182-194.

43 G. Dong, H. Wang, W. Liu, J. Shi, S. Sun, D. Li, H. Zhang, Y. Yang and Y. Cui, ACS Appl. Energy Mater., 2018, 1, 56365645.

44 Z. Xu, F. Xie, J. Wang, H. Au, M. Tebyetekerwa, Z. Guo, S. Yang, Y. S. Hu and M. M. Titirici, Adv. Funct. Mater., 2019, 1903895.

45 M. Sevilla, C. Sanchís, T. Valdés-Solís, E. Morallón and A. B. Fuertes, Carbon, 2008, 46, 931-939.

46 R. Yan, E. Josef, H. Huang, K. Leus, M. Niederberger, J. P. Hofmann, R. Walczak, M. Antonietti and M. Oschatz, Adv. Funct. Mater., 2019, 29, 1902858.

47 Y. Wang, Y. Li, S. S. Mao, D. Ye, W. Liu, R. Guo, Z. Feng, J. Kong and J. Xie, Sustainable Energy Fuels, 2019, 3, 717-722.

48 C. Lu, D. Wang, J. Zhao, S. Han and W. Chen, Adv. Funct. Mater., 2017, 27, 1606219.

49 Z. Peng, Y. Hu, J. Wang, S. Liu, C. Li, Q. Jiang, J. Lu, X. Zeng, P. Peng and F. F. Li, Adv. Energy Mater., 2019, 9, 1802928.
50 L. Hu, Q. Zhu, Q. Wu, D. Li, Z. An and B. Xu, ACS Sustainable Chem. Eng., 2018, 6, 13949-13959.

51 P. Pachfule, D. Shinde, M. Majumder and Q. Xu, Nat. Chem., 2016, 8, 718-724.

52 S. Yang, S. Wang, X. Liu and L. Li, Carbon, 2019, 147, 540549.

53 H. Chen, T. Liu, J. Mou, W. Zhang, Z. Jiang, J. Liu, J. Huang and M. Liu, Nano Energy, 2019, 63, 103836.

54 J. Xu, M. Wang, N. P. Wickramaratne, M. Jaroniec, S. Dou and L. Dai, Adv. Mater., 2015, 27, 2042-2048.

55 C. Long, L. Jiang, X. Wu, Y. Jiang, D. Yang, C. Wang, T. Wei and Z. Fan, Carbon, 2015, 93, 412-420.

56 D. Hulicova-Jurcakova, M. Seredych, G. Q. Lu and T. J. Bandosz, Adv. Funct. Mater., 2009, 19, 438-447.

57 Z. Li, Z. Xu, H. Wang, J. Ding, B. Zahiri, C. M. B. Holt, X. Tan and D. Mitlin, Energy Environ. Sci., 2014, 7, 1708-1718.

58 Z. Li, Z. Xu, X. Tan, H. Wang, C. M. B. Holt, T. Stephenson, B. C. Olsen and D. Mitlin, Energy Environ. Sci., 2013, 6, 871878.

59 B. Kruner, A. Schreiber, A. Tolosa, A. Quade, F. Badaczewski, T. Pfaff, B. M. Smarsly and V. Presser, Carbon, 2018, 132, 220-231.

60 D. W. Wang, F. Li, L. C. Yin, X. Lu, Z. G. Chen, I. R. Gentle, G. Q. Lu and H. M. Cheng, Chem.-Eur. J., 2012, 18, 53455351.

61 Y. J. Oh, J. Yoo, Y. K. Yoon, H. N. Yoon, J. H. Kim and S. B. Park, Electrochim. Acta, 2014, 116, 118-128.

62 D. Hulicova-Jurcakova, M. Kodama, S. Shiraishi, H. Hatori, Z. H. Zhu and G. Q. Lu, Adv. Funct. Mater., 2009, 19, 18001809.

63 C. Liu, F. Yi, D. Shu, W. Chen, X. Zhou, Z. Zhu, R. Zeng, A. Gao, C. He and X. Li, Electrochim. Acta, 2019, 319, 410-422.

64 J. Hou, C. Cao, F. Idrees and X. Ma, ACS Nano, 2015, 9, 25562564.

65 L. Wei, M. Sevilla, A. B. Fuertes, R. Mokaya and G. Yushin, Adv. Funct. Mater., 2012, 22, 827-834.

66 Z. Yanwu, M. Shanthi, M. D. Stoller, K. J. Ganesh, C. Weiwei, P. J. Ferreira, P. Adam, R. M. Wallace, K. A. Cychosz and T. Matthias, Science, 2011, 332, 1537.

67 M. Rose, Y. Korenblit, E. Kockrick, L. Borchardt, M. Oschatz, S. Kaskel and G. Yushin, Small, 2011, 7, 1108-1117.

68 L. Guan, L. Pan, T. Peng, C. Gao, W. Zhao, Z. Yang, H. Hu and M. Wu, ACS Sustainable Chem. Eng., 2019, 7, 8405-8412.

69 L. Estevez, V. Prabhakaran, A. L. Garcia, Y. Shin, J. Tao, A. M. Schwarz, J. Darsell, P. Bhattacharya, V. Shutthanandan and J. G. Zhang, ACS Nano, 2017, 11, 11047-11055.

70 F. Zheng, Y. Yang and Q. Chen, Nat. Commun., 2014, 5, 5261.

71 H. Zhang, X. Xu, H. Wang, Y. Lyu, X. Liu, Y. Zhao, J. Shi, W. Liu, E. Paek and D. Mitlin, ACS Sustainable Chem. Eng., 2018, 7, 2867-2877.

72 Z. Weng, F. Li, D. W. Wang, L. Wen and H. M. Cheng, Angew. Chem., Int. Ed., 2013, 52, 3722-3725.

73 V. Augustyn, J. Come, M. A. Lowe, J. W. Kim, P. L. Taberna, S. H. Tolbert, H. D. Abruna, P. Simon and B. Dunn, Nat. Mater., 2013, 12, 518-522. 